\title{
Implementation of Computer Assisted Experimental Work in Analytical Chemistry Laboratory Teaching
}

Jaume Albiol-Chiva1, Juan Peris-Vicente ${ }^{2}$, María José Ruiz-Ángel ${ }^{2}$, Mar EsteveAmorós $^{3}$, Samuel Carda-Broch ${ }^{1}$, Pau Esteve-Amorós ${ }^{4}$, Estel·la Esteve-Amorós ${ }^{5}$, Diego Kassuha $^{6}$, Josep Esteve-Romero ${ }^{1}$

${ }^{1}$ Química Bioanalítica, QFA, ESTCE, Universitat Jaume I, Castelló, Spain, ${ }^{2}$ Factultat de Químiques, Universitat de València, Burjassot, Spain, ${ }^{3}$ Facultat de Magisteri, Universitat de València, València, Spain, ${ }^{4}$ Enginyeria Industrial, Universitat Politècnica de Catalunya, Barcelona, Spain,, ${ }^{5}$ Arquitectura Tècnica, Universitat Politècnica de València, Spain, ${ }^{6}$ Facultad de Bioquímica, Universidad Católica de Cuyo, San Juan, Argentina.

\begin{abstract}
Computer-Assisted Experimental Work (CAEW) consists in the incorporation of computer-connected apparatus in the laboratory. This is a new insight into teaching of Classical Analytical Chemical, wherein the experiments are usually manually conducted. However, it does not represent a complete break with traditional methodology, as the design and goal of the experiment are essentially the same.

In this work, we present the implementation of CAEW to a practical included in the Laboratory part of "Analytical Chemistry IV", taught at the fourth anademic year of the Degree in Chemistry: "Potentiometric titration of a mixture of iodure and chlorure with silver". Three couples of students used an Ag-ion selective electrode connected to a computer, while the other three couples employed a digital one. The results were comparable, though the computer-assisted method provided significant improvements, like: the students get familiar with new technologies at an accessible level, the titration can be visually followed on the screen via the titration curve, the calculations are automatically performed, it allows the detection of experimental and registration mistakes, it avoids errors caused by the transcription and processing of the data,and the students achieve their practical disposing of the final results, and all their work corrected by the teacher.
\end{abstract}

Keywords: Chemistry; Computer-assisted; Precipitation; Teaching; Titration; University. 


\section{Introduction}

This work has been developed in teaching laboratories at the Universitat Jaume I (UJI) in collaboration with a secondary school of Vila-real, IES Vicente Castell. The IES provided the software DataStudio (ref. CI-6859C), the Ag-ion selective electrode (ref.2104) and the adapter "USB-Link" (Ref.PS-2100) and their respective hardware and software. They were made by PASCO (http://www.pasco.com) and marketed by PRODEL teaching equipment (http://www.prodel.es).

The tested laboratory practical was: "Potentiometric titration of a mixture of iodure and chlorure with silver" (Sawyer \& Heneiman, 2002), which is included in the Laboratory part of the subject "Analytical Chemistry IV" (QU927), taught at the fourth (last) anademic year of the Degree in Chemistry at the University Jaume I (UJI Virtual Classroom https://aulavirtual.uji.es/?lang=es; Esteve-Romero, 2006).

The students had to conduct the precipitation titration in aqueous media of a mixture of iodure and chlorure with silver(I). The titration reactions were the successive precipitation of both anions with $\mathrm{Ag}^{+}$(stoichiometry 1:1), first the iodure and later the chlorure. The end point was detected by the monitoring of the potential measured by an Ag-ion selective electrode (ISE) v.s. titrant volume (Harvey, 2016). The goal of the practical was to quantify iodure and chlorure in the sample, and to calculate the Kps of their respective precipitates with silver. The practical belongs to Classical Analytical Chemistry. This branch of the Analytical Chemistry aims to identify/quantify/determine the physico-chemical properties of the analytes by means of their reactivity. It uses traditional laboratory glassware and apparatus, and the experiments are manually carried out (Monferrer-Pons \& EsteveRomero, 1996; Skoog et al., 2013). The incorporation of a computer-connected device represent a significant and revolutionary innovation in this area (Esteve-Romero \& CardaBroch, 1998; Gil-Agustí et al., 2009a). This fits with the guidelines of the European Higher Education Area (EHEA), which stated that the student must be at the center of the teachinglearing process. That means modifications leading to an increase of the students background should be developed (Gil-Agustí et al., 2009b).

The aim of this the was to compare the classical and CAEW approaches (considering the entire execution of the practical, the data registration and processing, time taken to achieve the practical and the post-practical work, as well as the analytical quality of the results), and to establish their respective advantages and drawbacks.

\section{Experimental procedure}

The practical was conducted by pairs of students, as usual in the Analytical Chemistry Laboratory. The students perform the titration following the Good Laboratory Practices 
(GLP) guidelines (Gil-Agustí et al., 2009c). Half of the students performed the practical using an Ag-ISE connected to a computer (couples CAEW-1; 2 and 3), while the other ones utilized a digital one (control couple-1; 2 and 3). Apart from this, the practical was conducted as the same way. Only the work performed by the CAEW couples is here described.

The titrant was a solution of $\mathrm{AgNO}_{3} 0.9994 \mathrm{M}$, while the sample was a solution of $\mathrm{I}^{-}$and $\mathrm{Cl}^{-}$at unknown concentrations, acidified with drops of $\mathrm{HNO}_{3}$ and salt-buffered with $\mathrm{Ba}\left(\mathrm{NO}_{3}\right)_{2}$. The Ag-ISE was cleaned by polishing, in order to remove low-soluble silver precipitates adsorbed on the surface, remove fissures and homogeneize it (Harvey, 2016).

\subsection{Software configuration}

Once opened the DataStudio software and connected the Ag-ISE using the UBS-link to a computer's USB port, a window displayed a plot of potential vs. titrant volume and the axis configuration.

The next step required the performing of some simple initial operations for the software configuration. a) Set the manual entry of the volume. The selection of the option "Setup and sampling options" opened the window for manual input of a magnitude of the x-axis. The name (Volum Ag), and the unity (mL) and the associated precision $(\mathrm{mL})$ of the titrant solution had to be introduced. Once at this point, return to the initial screen and the software was already ready.

\subsection{Titration process}

Firstly, the titrant was introduced in the buret, and then an aliquot of the sample (the titrand) was introduced in the erlenmeyer flask, which was placed under the buret. Secondly, the Ag-ISE was introduced in the titrand solution. Afterwards, the titration could begin. As in a traditional titration, several volumes $(\mathrm{mL})$ were added from the buret. Before the addition of the first $\mathrm{mL}$, the start button, appearing on the top left of the scree had to be pressed. An option showed up, where the titrating volume was asked. After pusing 0, the first pair of data was taken. Every time the titrant was added and the solution homogenized, the button "Start" was pushed again to introduce the volume added. In this way, the plot of E vs. titrating volume was constructed. The titrant was added in $0.5-\mathrm{mL}$ steps as a general rule, and by $0.1-\mathrm{mL}$ steps when close to the end point. The titration was finished when the addition of silver solution does not significantly increase the signal, far from the second end point.

For the control group, the titration was conducted alike, but the experimental data of volume and potential manually were manually recorded. 


\subsection{End point determination}

The titration end points were determined by the first and the second derivative, as well as the Grau methods (Harris, 2007). The software itself drew the corresponding plots, and calculated the end point volume and potential.

\subsection{Calculation of the Kps}

The potential, at any point of the titration curve, follows the equation (Harris, 2007):

$$
\mathrm{E}=\mathrm{E}^{0}+0.059 \log \left[\mathrm{Ag}^{+}\right]
$$

To calculate $\mathrm{E}^{0}$, we have to measure the potential far from the end point, after the total precipitation of the analytes. In this region, there is a large excess of free $\mathrm{Ag}^{+}$in the solution, and its concentration can be easily calculated by the following equation:

$\mathrm{n}\left(\mathrm{Ag}^{+}\right)$consumed by the titration $=\mathrm{n}\left(\mathrm{I}^{-}\right)_{0}+\mathrm{n}\left(\mathrm{Cl}^{-}\right)_{0}+\mathrm{n}\left(\mathrm{Ag}^{+}\right)$free

Once $\left[\mathrm{Ag}^{+}\right]$known, we can calculate $\mathrm{E}^{0}$.

For both anions, the precipitation equilibria product $\left(\mathrm{Kps}=\left[\mathrm{Ag}^{+}\right]\left[\mathrm{X}^{-}\right]\right)$is valid as long as $\mathrm{AgX}, \mathrm{X}^{-}$and $\mathrm{Ag}^{+}$coexist in the solution, then in any point of the curve. Additionally, at the equivalence point, we have $\left[\mathrm{Ag}^{+}\right]=\left[\mathrm{X}^{-}\right]$, then $\mathrm{Kps}=\left[\mathrm{Ag}^{+}\right]^{2}$.

We need to know the potential at the first and second end point for $\mathrm{I}^{-}$and $\mathrm{Cl}^{-}$, respectively, and substitute in equation (1). Then we will calculate $\left[\mathrm{Ag}^{+}\right]$and Kps.

\section{Results}

The students did not have any problem to understand the use of the software and hardware. Indeed, they are highly-skilled (they are close to the completition of the degree) and its manipulation is very simple. In fact,the experimental work conducted by the students using CAEW and classical procedure was essentially the same.

One of the high advantages that EXAO introduces is the possibility of monitoring step by step the titration, by the configuration of the precipitation titration curve. In the traditional methods, the use of a digital Ag-ISE to follow a potentiometric titration requires that the student manually register the data, transcribe them to a separate office spreadsheet and then build a graph. If the titration is followed by a change in the colour of a chemical indicator, there is even no possibility to construct a plot.

EXAO also introduced the option of a direct calculation of the end point volume and potential using either the first or second derivative, or the Grau methods. This enabled the students to achieve the objectives of the practical: the calculation of the concentration of $\mathrm{I}^{-}$ and $\mathrm{Cl}^{-}$and the Kps of AgI and AgCl. In the traditional approach, this was made by 
introducing the formula and manipulating the data on an office spreadsheet, thus increasing the risk of processing errors.

Only the results obtained by the couple of students using EXAO are shown. Figure 1 shows the raw titration curve. Figure 2; 3 and 4 show the curves obtained by applying the first and second derivative, and the Grau methods, respectively.

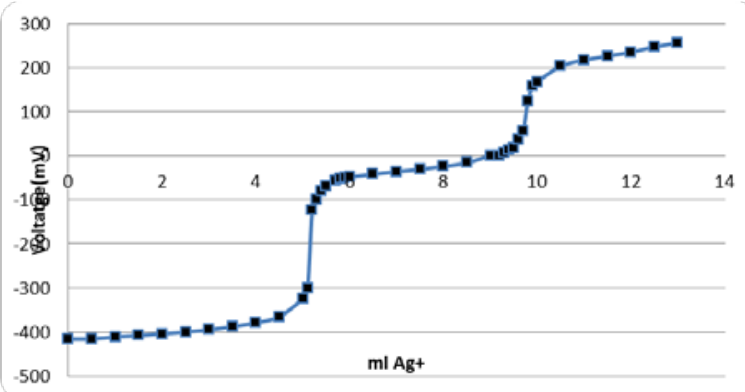

Figure 1. Titration curve.

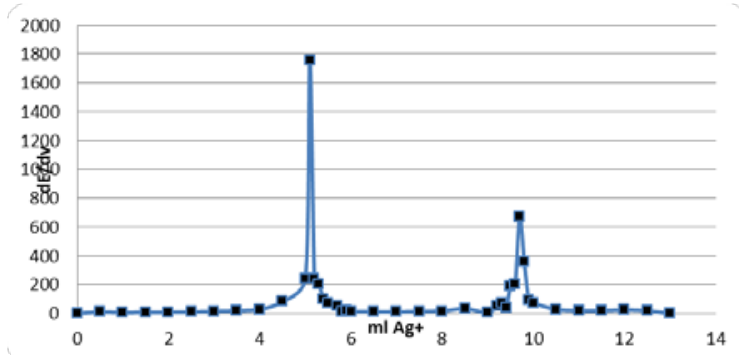

Figure 2. Curve obtained by the first derivative method.

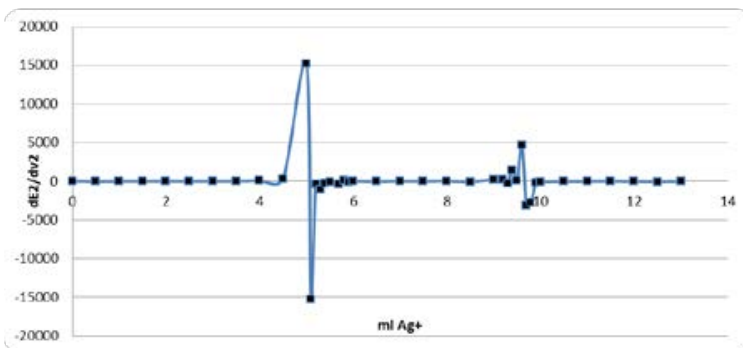

Figure 3. Curve obtained by the second derivative method. 


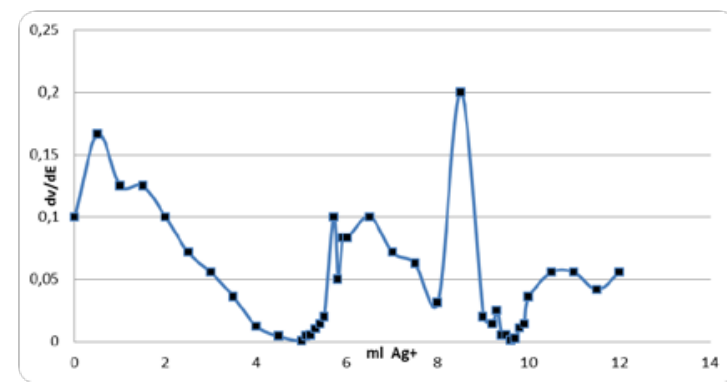

Figure 4. Curve obtained by the Grau method.

Regardless of the method used, the end point volumes were $5.1 \mathrm{~mL}$ and $9.7 \mathrm{~mL}$. The first end point correspond to iodure and the second one to chlorure, as AgI is more unsoluble than AgCl. The theoretical value of $\mathrm{pKps}(\mathrm{AgCl})$ and $\mathrm{pKps}(\mathrm{AgI})$ were 10.2 and 22.2, respectively; close enough to the tabulated values (10.7 and 22.0). The control couples obtained similar results.

All the students took similar time to achieve the practical. At the end of the session, the CAEW group have finished all the calculations and disposed of the results, automatically provided by the sotware. Besides, they were able to have their work corrected by the teacher, and could discuss the obtained values with him. The control couples only had the raw data; and had to perform their calculations after the laboratory session, by transcribing the hand-recordered data to a separate office spreadsheet.

Each couple were in the risk of making the following mistakes during the development of the practical and the elaboration of the post-pastical work was as follows:

- CAEW couples: experimental and recording of the titrant volume (the potential values were automatically collected by the software).

- Control couples: experimental, registration of both titration volume and potential, transcription and processing.

However, the CAEW couples were able to notice the errors during the laboratory session, in time to correct them, unlike the control couples.

\section{Conclusions}

The results obtained using CAEW and the tratidional method were similar in analytical quality. The use of CAEW exhibits the following advantages:

- It introduces the use of new technologies to students.

- It was not a complete break with traditional methods because the classical experiments were still working. Therefore, the students can easily adapt to it and interprete the results. 
- It used software that permits to understand, visualize and process the experimental data, during the conduction of the practical. Besides, it automatically provided the main analytical parameters of the titration: end point volume and potential.

- Experimental and recording errors can be immediately noticed and corrected.

- Transcription or processing errors can hardly occur.

- All the post-practical work can be performed during the laboratory session, under the supervision of the teacher.

However, we must point the following drawback:

- Each couple of students must have a laptop or PC in the laboratory, thus increasing the cost of the practical.

The introduction of this methodology would ameliorate the teaching-learning process at the Chemical Laboratory, and then improve the background of the students. Therefore, this is highly interesting for a subject designed following the guidelines of the European Higher Edcation Area, which stated that the student must be at the center of the education system (Gil-Agustí et al., 2009b).

\section{Acknowledgements}

The work was carried ouy thanks to the financement of Educational Support Unit Unitat de Suport Educatiu of the University Jaume I, by projects GIE 2018/2019-Química Bioanalítica 3603 and GIE-Teaching Innovation 3603/18.

\section{References}

Esteve-Romero, J.S., \& Carda-Broch, S. (1998). Automatització del laboratori químic. Castelló: Universitat Jaume I.

Esteve-Romero, J.S. (2006). Canvi en la metodologia i avaluació de la IA29: Química Analítica Avançada. Qualitat educativa i millora docent a l'Espai Europeu d'Educació Superior. Castelló: Universitat Jaume I.

Gil-Agustí, M.T., Esteve-Romero, J.S., Carda-Broch, S., \& Monferrer-Pons, J.L. (2009a). Innovació en el laboratori químic: proposta de canvi en la metodologia i avaluació. Mejora e innovación educativa en el Espacio Europeo de Educación Superior. Castelló: Universitat Jaume I.

Gil-Agustí, M.T., Carda-Broch, S., Rambla-Alegre, M., \& Esteve-Romero, J.S. (2009b). Noves metodologies per a la innovació en la docència d'assignatures de laboratori en la Llicenciatura de Química. Metodologías centradas en el estudiante en el Espacio Europeo de Educación Superior. Castelló: Universitat Jaume I. 
Gil-Agustí, M.T., Esteve-Romero, J.S, Carda-Broch, S., \& Monferrer Pons, J.L. (2009c). Operacions bàsiques al laboratori químic seguint normes de qualitat. Metodologías centradas en el estudiante en el Espacio Europeo de Educación Superior. Castelló: Universitat Jaume I

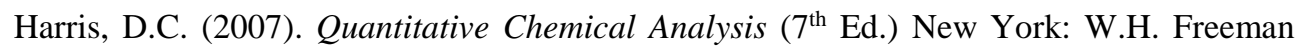
and Company).

Harvey D. (Ed.). (2016). Analytical Chemistry 2.1. Greencastle: DePaw University

Monferrer-Pons, J.L., \& Esteve-Romero, J.S. (1996) Separacions i identificacions en química analítica. Castelló: Universitat Jaume I.

Skoog, D.A., West, D.M., \& Holler, F.J. (2013). Fundamentals of Analytical Chemistry (9th ed.). Boston: Cengage Learning.

Sawyer, D.T., \& Heneiman, W.R. (2002). Chemistry Experiments for Instrumental Analysis ( $2^{\text {nd }}$ ed.). New York: Wiley. 